\title{
Advanced glycation end products increased placental vascular permeability of human BeWo cells via RAGE/NF-kB signaling pathway
}

\section{Yuehua Shi}

Southeast University Zhongda Hospital

Jie Qian

Nanjing University of Chinese Medicine

Qinfen Zhang

Southeast University Zhongda Hospital

Yan $\mathrm{Hu}$

Southeast University Zhongda Hospital

\section{Dongdong Sun}

Nanjing University of Chinese Medicine

\section{Li Jiang ( $\nabla$ yuehuashi82@163.com )}

Southeast University Zhongda Hospital

\section{Research}

Keywords: Advanced Glycation end products, human BeWo cells, tight junctions, RAGE/NF-kB pathway

Posted Date: February 14th, 2020

DOl: https://doi.org/10.21203/rs.2.23585/v1

License: () (1) This work is licensed under a Creative Commons Attribution 4.0 International License. Read Full License

Version of Record: A version of this preprint was published at European Journal of Obstetrics \& Gynecology and Reproductive Biology on July 1st, 2020. See the published version at https://doi.org/10.1016/j.ejogrb.2020.04.058. 


\section{Abstract}

Background: The placental barrier plays an important role in protecting the fetus from the maternal environment. Gestational diabetes mellitus (GDM), caused by placental permeability, is a serious pregnancy complication with a high incidence worldwide. This study aimed to investigate the effects of advanced glycation end products (AGEs) on cell tight conjunction, and explore underlying mechanisms of the dys-regulation of placental vascular permeability in BeWo cells.

Methods: Monolayer permeability assay was employed to reveal the transformation of the placental vascular permeability in BeWo cells under different administrations. Transmission electron microscopy was utilized to evaluate cell tight conjunction of BeWo cells. Immunofluorescence, wetern blot and RTqPCR were adopted to determine the protein and mRNA levels of ZO-1, Occludin, RAGE and NF-kB. In addition, anti-RAGE and NF-kB inhibitor (PDTC) were used to inactivate the RAGE/NF-kB signaling pathway.

Results: AGEs significantly decreased trans-epithelial electrical resistance (TEER), while increased paracellular permeability $(P<0.05)$. TEM results showed that AGEs made the cell junction loose. Immunofluorescence, wetern blot and RT-qPCR analyses showed that AGEs significantly inhibited the expressions of ZO-1 and Occludin, while anti-RAGE or PDTC partially restored their levels. Besides, AGEs also significantly increased the expressions of mRNA RAGE and NF-kB in BeWo cells $(P<0.05)$, and their expressions were inhibited by anti-RAGEy or PDTC.

Conclusion: AGEs could reduce the expressions of ZO-1 and Occludin by activating RAGE/NF-kB signaling pathway, thus increasing placental vascular permeability of BeWos cells. These findings would provide a novel sight for improving the development and prognosis of GDM.

\section{Background}

The placental barrier, served as the interface between the environments of fetus and maternal, protects the fetus both from pathogens and from rejection by the maternal immune system, and functions as a nutrient transfer and endocrine organ (1). Increasing evidences indicated that placental structural and functional abnormalities can cause numerous adverse pregnancy outcomes (2). Gestational diabetes mellitus (GDM) is initiated occurrence characterized by abnormal glucose tolerance and the most frequent metabolic complication affecting women during pregnancy (3). Previous studies showed that placental vascular permeability is mainly caused by hyperglycemia, and insulin therapy does not improve interendothelial junctions and reduce the risk of pre-eclampsia (4-6). Therefore, finding and regulating factors that lead to changes in placental vascular permeability are very important for improving the development and prognosis of GDM.

Advanced glycation end products (AGEs), formed in diabetes mellitus (DM), is associated with glomerular microvascular disease, including diabetic retinopathy and diabetic nephropathy $(5,6)$. Besides, it has been recently reported that AGEs are involved in inducing changes in the distribution of interendothelial 
junctions and endothelial cell permeability in diabetic patients with microvascular complications $(7,8)$. AGEs in serum are also higher in GDM patients compared to that of non-diabetics, which appears to account for placental bed vascular changes and is considered to be related to adverse fetal outcome and occurrence of preeclampsia (9-12). Therefore, it could be speculated that AGEs may be an important factor for changes in placental permeability.

In addition, AGEs played harmful effects mainly via two main pathogenic pathways. Firstly, due to the cross-linking effect of collagen and elastin, AGEs have the potential to form cross-links, which results in impaired protein function and turnover, and the increase of tissue stiffness (13). Activation of paracellular pathways is important for increase of placental permeability (14). Another pathway is that AGEs may also bind to cell membrane receptors to release pro-inflammatory cytokines, which thereby enhances inflammatory reactions (15). Receptor for Advanced Glycation End products (RAGE), a receptor for AGEs, was expressed in the human placenta, and may be an important modulator of the deleterious effects of inflammatory compounds (16). Hence, we hypothesized that there might be a correlation among AGEs, tight conjunctions dysfunction and RAGE in human placental barrier, which may play roles in the pathophysiology of GDM.

In this study, the choriocarcinoma cell line BeWo was used as the experimental model to investigate the effects of AGEs on cell tight conjunctions, and explore the underlying mechanisms of the dysregulation of placental vascular permeability in BeWo cells. These findings would provide a new sight for improving the development and prognosis of GDM.

\section{Methods}

\section{Preparation of AGEs-BSA}

AGEs-BSA (pH 7.4) was prepared by incubation of BSA (Fraction V, Sigma Chemical Co., St. Louis, MO, USA) at a concentration of $50 \mathrm{mg} / \mathrm{mL}$ with $0.5 \mathrm{M}$ glucose in $0.2 \mathrm{M}$ phosphate-buffered saline (PBS) containing penicillin (100 U/ml, Sigma-Aldrich, St Louis, Mo, USA) and gentamicin (70 $\mu \mathrm{g} / \mathrm{ml}$, SigmaAldrich) at $37^{\circ} \mathrm{C}$ for 12 weeks. Free glucose was removed by extensive dialysis against PBS. For a control group, BAS incubation solution containing no glucose was also prepared for 12 weeks. The AGEs-BSA level was determined by fluorescence spectrophotometer. The concentrations of AGEs in the prepared AGEs-BSA sample and BSA control were $25 \mathrm{mg} / \mathrm{ml}$ and $0.8 \mathrm{mg} / \mathrm{ml}$, respectively.

\section{Cell culture and treatment}

BeWo cell lines were donated by Jiayin Liu Laboratory of Nanjing Medical University and cultured according to the supplier's instructions. The cells were maintained at standard culture conditions of $5 \%$ $\mathrm{CO}_{2}$ in air at $37^{\circ} \mathrm{C}$. Cells were grown in an adherent condition in Ham's F12 medium (Sigma-Aldrich, St Louis, Mo, USA) containing 10\% fetal bovine serum (FBS, Culti-lab), $100 \mathrm{U} / \mathrm{mL}$ penicillin and $100 \mu \mathrm{g} / \mathrm{mL}$ streptomycin. The cells were seeded into 24 -well plates at $1 \times 10^{4}$ cells/well to form a confluent monolayer, and then switched to the medium without FBS to induce differentiation. When the cells 
reached to $70 \%$ - $80 \%$ confluence, different concentrations $(0 \mu \mathrm{g} / \mathrm{mL}, 50 \mu \mathrm{g} / \mathrm{mL}, 100 \mu \mathrm{g} / \mathrm{mL}, 200 \mu \mathrm{g} / \mathrm{mL}$, $400 \mu \mathrm{g} / \mathrm{mL}$ ) of AGEs-BSA were added to the medium for various times ( $6 \mathrm{~h}, 12 \mathrm{~h}$ and $24 \mathrm{~h}$ ). Besides, antiRAGE $(10 \mu \mathrm{g} / \mathrm{mL}$, Abcam, Cambridge, UK ) or ammonium pyrrolidinedithiocarbamate (PDTC, $100 \mu \mathrm{M} / \mathrm{mL}$, Beyotime Co. Ltd, Shanghai, China) were added to the medium for $2 \mathrm{~h}$ before treatment with optimal concentration of AGEs-BSA.

\section{Monolayer permeability assay}

BeWo cells integrity was investigated by measuring the trans-epithelial electrical resistance (TEER) in a 12-well transwell plate $\left(1.0 \mu \mathrm{m}\right.$ pore size, $0.3 \mathrm{~cm}^{2}$ membrane surface area, Millicell Hanging cell culture inserts, Japan Millipore Co., Tokyo, Japan). BeWo cells $\left(1 \times 10^{5}\right.$ cells/well) were seeded into transwell inserts, and cultured using CS-C cell culture medium (Sigma-Aldrich, St Louis, Mo, USA). After treated with different concentrations of AGEs-BSA for different times, the TEER of monolayer cells were determined. An equal volume of culture medium without cells was served as the blank control. According to the manufacturer's instructions, TEER of monolayer was calculated as following:

TEER of monolayer $\left(\Delta \Omega \mathrm{cm}^{2}\right)=($ sample-well resistance - blank-well resistance $) \times$ area of cell monolayer.

In addition, paracellular permeability was measured using $70 \mathrm{kDa}$ fluorescein isothiocyanate (FITC)dextran (final concentration $100 \mu \mathrm{g} / \mathrm{mL}$, Sigma-Aldrich, St. Louis, MO, USA), which was added to transwell inserts and incubated for $4 \mathrm{~h}$ in $\mathrm{CO}_{2}$ incubator. The amount of fluorescence on the basolateral side medium was collected from trans-well inserts and bottom chambers. Subsequently, the fluorescenceintensity of FITC-dextran was determined at the excitation and emission wavelengths of 485 and $538 \mathrm{~nm}$, respectively. Finally, the leakage of FITC-dextran was evaluated as follows:

Permeability $(\%)=($ FITC-dextran content in bottom chamber / (FITC-dextran content in transwell insert + bottom chamber) $) \times 100$.

\section{Transmission electron microscopy (TEM)}

BeWo cells were fixed with $2.5 \%$ glutaraldehyde for $1 \mathrm{~h}$, and then transferred to $0.05 \mathrm{M}$ sucrose solution $(\mathrm{pH} 7.2)$ and stored at $4{ }^{\circ} \mathrm{C}$. Subsequently, the cells were post-fixed in $1 \%$ osmium tetroxide at $4{ }^{\circ} \mathrm{C}$ for $1 \mathrm{~h}$, and then added to acetone. After embedded in araldite, $0.5 \mu \mathrm{m}$ semi-thin sections were cut, and the structure of all cells were systematically investigated at $20000 \times$ magnification by an electron microscope (EVO MA 10, ZEISS, Germany).

\section{Immunofluorescence staining}

Immunofluorescence was analyzed by immunelabeling for ZO-1 and Occuludin. BeWo cells were seeded in 24-well plates and cultured in RPMI 1640 medium containing 10\% FBS. After treated with different reagents at indicated concentrations for $24 \mathrm{~h}$, the cells were incubated with rabbit anti-zonular occludens1 (ZO-1) (1:1000, Invitrogen, Thermo Fisher Scientific, Inc., USA) and rabbit anti-Occludin (1:2000, Abcam, Cambridge, UK) at $4^{\circ} \mathrm{C}$ overnight, and then incubated with horseradish peroxidase (HRP)-conjugated goat 
anti-rabbit secondary antibody (1:500, Abcam). The nucleus of each cell was stained with Hoechst 33342 (Blue). Images were taken of random fields at $200 \times$ magnification.

\section{Western blot analysis}

Total proteins of cells were obtained by RIPA Lysis buffer (Beyotime Biotechnology, Jiangsu, China). The proteins were separated by $10 \%$ SDS-PAGE, transferred to polyvinylidene fluoride (PVDF) membranes (Invitrogen, Carlsbad, CA, USA), and blocked with TBST containing $1.5 \%$ BSA at $26^{\circ} \mathrm{C}$. After $2 \mathrm{~h}$, the membranes were incubated with anti-ZO-1 antibody (1:1000, Invitrogen), anti-Occludin antibody (1:2000, Abcam), anti-RAGE antibody (1:500, Abcam), anti-NF-kB p65 antibody (1:1000, Abcam) and anti-GAPDH antibody (1:4000, Abcam), respectively, at $4^{\circ} \mathrm{C}$ overnight. After washed three times, the membranes were incubated with HRP-conjugated goat anti-rabbit secondary antibody $\left(1: 500\right.$, Abcam) at $37^{\circ} \mathrm{C}$ for $2 \mathrm{~h}$. The protein bands were visualized with ECL kit (Thermo Fisher Scientific, Rockville, MD, USA), and images were taken with image lab software (Bio-Rad, Hercules, CA, USA).

Real-time quantitative polymerase chain reaction (RT-qPCR)

Total RNA was extracted using TRIzol reagent (Invitrogen, Carlsbad, CA, USA) according to the manufacturer's instructions. The RNA concentration and quality were evaluated using a NanoDrop 2000 spectrophotometer (Thermo Fisher Scientific Inc., DE, USA). Afterwards, $0.2 \mu \mathrm{g}$ RNA was reversely transcribed to cDNA using a PrimeScript RT reagent kit (TakaraBio, Tokyo, Japan) based on the manufacturer's instructions. All primers were designed and synthesized by Sangon Biotech (Shanghai) Co. Ltd (Shanghai, China), and the sequences of all primers were listed in Table 1. The total volume of RTqPCR reaction was $20 \mu \mathrm{L}$, including $10 \mu \mathrm{L}$ SYBR Green supermix, $1 \mu \mathrm{L}$ forward primer $(10 \mu \mathrm{M} / \mathrm{L}), 1 \mu \mathrm{L}$ reverse primer, $2 \mu \mathrm{L} \mathrm{CDNA}$ and $6 \mu \mathrm{L}$ distilled water. The amplification conditions were as follows: $95^{\circ} \mathrm{C}$ for $10 \mathrm{~min}, 40$ cycles of $95^{\circ} \mathrm{C}$ for $15 \mathrm{~s}$ and $60^{\circ} \mathrm{C}$ for $1 \mathrm{~min}$. The relative mRNA expression levels were calculated via $2^{-\triangle \triangle C T}$ method (17), and normalized with the expression of GAPDH.

\section{Statistical analysis}

All experiments were performed in triplicate. The data were expressed as mean \pm standard deviation (SD) in this study. The results were statistically analyzed using GraphPad Prism 5 (GraphPad software Inc., San Diego, CA, USA). The statistical significance of difference among multiple groups was tested and determined via two-way analysis of variance (ANOVA) followed by post-hoc Student-Newman-Keuls test. $P$ value less than 0.05 was considered statistically significant.

\section{Results}

\section{The effects of AGEs on TEER and paracellular permeability in BeWo cells}


To reveal the underlying regulation mechanisms of placental integrity by AGEs, the effects of AGEs on vascular endothelial cell integrity were investigated by measuring TEER and paracellular permeability. Compared with the control group, after administrated with AGEs, TEER was decreased (Fig. 1A), while the paracellular passage of FITC-dextran increased (Fig. 1B) in a time-dependent manner. However, there was no significant difference in TEER and paracellular passage of FITC-dextran among the cells respectively treated with $100 \mu \mathrm{g} / \mathrm{mL}, 200 \mu \mathrm{g} / \mathrm{mL}$ and $400 \mu \mathrm{g} / \mathrm{mL}$ AGEs for $24 \mathrm{~h}$ ( $P>0.05$, Fig. 1A, B). Therefore, $100 \mu \mathrm{g} / \mathrm{mL}$ AGEs and $24 \mathrm{~h}$ culture time were selected for further experiments.

As shown in Fig. 1C, D, AGEs greatly decreased TEER, and increased paracellular passage of FITC-dextran compared with the control group $(P<0.05)$. After co-treated with anti-RAGE, the levels of TEER and paracellular passage of FITC-dextran were retrieved partly, while there was a significant difference compared to the control group $(P<0.05)$. Similarly, PDTC could significantly restore the levels of TEER and paracellular passage of FITC-dextran induced by AGEs $(P<0.05$, Fig. 1E, F). Taken together, AGEs could induce vascular endothelial permeability and disturb the physiological barrier of capillary endothelium as evidenced by dys-regulation of TEER and paracellular passage of FITC-dextran. Besides, anti-RAGE and PDTC could partially restore the vascular endothelial permeability induced by AGEs.

\section{TEM analysis}

The results of TEM showed that the cell morphology was normal and intercellular connections were tight in the control group. After treated with AGEs, gaps appeared between cells and intercellular connections were loose, increasing the cell membrane permeability. However, anti-RAGE and PDTC could shorten the gaps between cells, and reduced the cell permeability (Fig. 2).

\section{Immunofluorescence analysis}

Further to explore the effects of AGEs on cell tight junctions, immunofluorescence was utilized to determine the relative protein expression levels of tight junction proteins, including ZO-1 and Occludin. Immunofluorescence results showed that the protein expression levels of ZO-1 and Occludin were decreased by AGEs compared with the control group, while anti-RAGE and PDTC recovered the protein levels of ZO-1 and Occludin caused by AGEs to a similar level of control group (Fig. 3A, B). The results indicated that AGEs could increase cell permeability by inhibiting the expression levels of tight junction proteins.

\section{Western blot analysis}

The protein levels of ZO-1, Occludin, RAGE, NF-kB were determined by western blot. The results showed that AGEs reduced the protein levels of ZO-1 and Occludin compared with the control group, and antiRAGE greatly restored their levels $(P<0.05$, Fig. $4 A, C)$. For the protein levels of RAGE and NF-kB, their levels were up-regulated by AGEs, while were down-regulated after treatment with anti-RAGE (Fig. 4A, C). Besides, the tendency of these protein expression levels treated with PDTC was similar with those treated with anti-RAGE (Fig. 4B, D). 


\section{RT-qPCR analysis}

The relative mRNA expressions of ZO- 1 in control group and AGEs group were $1.0 \pm 0.19$ and $0.23 \pm 0.03$, respectively, which indicated that AGEs could significantly inhibit the mRNA expression of ZO-1 $(P<0.05$, Fig. 5A). After co-treated with anti-RAGE and PDTC, its relative expression was severally up to $0.75 \pm 0.2$ and $0.76 \pm 0.04$, which demonstrated that anti-RAGE and PDTC may up-regulate the expression of ZO-1 (Fig. 5A). For the mRNA expression of Occludin, its change trend was similar with that of ZO-1 (Fig. 5B). In addition, the mRNA expressions of RAGE and NF-kB were significantly up-regulated by AGEs (Fig. 5C, D). After added anti-RAGE, the expression of mRNA RAGE was inhibited significantly $(P<0.05$, Fig. $5 C)$, while PDTC had no effect on the expression of RAGE. However, for the expression of NF-kB, anti-RAGE or PDTC could both down-regulate its expression (Fig. 5D). In brief, these results indicated that AGEs may up-regulate the expression of ZO-1 and Occludin via inhibiting the RAGE/NF-KB signaling pathway to increased placental vascular permeability of BeWo cells.

\section{Discussion}

AGEs, produced by the non-enzymatic glycation of proteins and lipids under hyperglycemia or oxidative stress conditions, were implicated to be pivotal in the development and progression of diabetic vascular complications, including GDM (18). In addition, AGEs could lead to hyper-permeability and barrier dysfunction in human umbilical vein endothelial cells $(18,19)$. In our study, AGEs were found to dysregulation of TEER and paracellular passage of FITC-dextran in BeWo cells, while anti-RAGE or PDTC interference could partially restore their levels. TEM results showed that cell tight conjunctions were changed by AGEs. Immunofluorescence, western blot and RT-qPCR showed that the expressions of ZO-1 and Occludin were down-regulated by AGEs, while their levels were up-regulated by anti-RAGE or PDTC. In addition, western blot and RT-qPCR also showed that RAGE and NF-kB were significantly up-regulated by AGEs, while anti-RAGE or PDTC could inhibit their expression levels.

Several studies have shown that AGEs in serum and placenta of GDM patients was greatly higher than that of normal pregnant women, suggesting the link between abnormal amount of AGEs and GDM development and progression $(20,21)$. In the present study, AGEs could decrease TEER and increase paracellular pathway, implying hyperpermeability by AGEs in BeWo cells. Besides, the cell tight conjunction in BeWo cells became loose, which indicated that AGEs may increase the placental vascular permeability in BeWo cells. When anti-RAGE or PDTC interfered, the cell permeability could be reduced. However, the mechanisms of AGEs on placental vascular permeability remain unclear.

Increasing evidences have shown that placental vascular permeability was associated with tight junction $(22,23)$. The tight junction, presented in both trophoblast cells and in fetal vessel epithelium, is an important structure of placental barrier, and plays a key role in maintenance of the cell membrane integrity, and regulation the function of placental barrier (24). ZO-1, as the intracellular component of tight junctions, interacted with adhesive proteins and regulated the tight junction' functions (25). Occludin, an essential substance of tight junction structure, played a permeability regulatory role and constituted a key 
fence in epithelium and endothelium in the blood-brain and blood-retinal barriers (26). A study of Sun et al. indicated that the combination of insulin and idebenone significantly strengthened the tight junction in diabetic rats by up-regulating tight junction-associated proteins Occludin and ZO-1 (27). In our study, the expression levels of ZO-1 and Occludin were greatly reduced by AGEs, suggesting the disruption of the tight junction structure; while their levels were elevated by the inference of anti-RAGE or PDTC. Combined with our results, it was speculated that AGEs may increase placental vascular permeability in BeWo cells via down-regulating the expressions of tight junction-associated proteins ZO-1 and Occludin.

In addition, RAGE and NF-kB were reported to be closely connected with cell function, and were found to be up-regulated in many inflammatory diseases, including diabetes, cardiovascular disease and cancer (28-30). RAGE, a transmembrane, multiligand receptor expressed by most cells, were highly expressed on the surface of placental trophoblast cells, and mediated cell adhesion to extracellular matrix components and to other cells through homophilic interactions $(16,31,32)$. Besides, a critical property of AGEs was the ability to activate RAGE expression, which further activated the pleiotropic transcription factor NF-kB to cause pathological changes $(33,34)$. Studies have indicated that AGEs could activate and transduce many intracellular signal transduction pathways, including p21ras, MAP kinases, PI3 kinase, NAD(P)H oxidase, resulting in activation of NF-kB $(35,36)$. Furthermore, Hirose et al. reported that AGEs induced hyper-permeability of human endothelial cells through RAGE/Rho signaling pathway (37). Another study of Feng et al. demonstrated that glycyrrhizic acid possessed protective effects on AGEs-induced endothelial dysfunction induced through suppressing RAGE/NF-kB pathway (38). In this study, the expression levels of RAGE and NF-kB were up-regulated by AGEs in BeWo cells, and after administrated with RAGE or PDTC inhibitor, their levels were restrained. Therefore, AGEs may inhibit the expressions of tight junction-associated proteins ZO-1 and Occludin through activating the RAGE/NF-kB signaling pathway, thus promoting placental vascular permeability of BeWo cells. However, the regulatory relationships and networks between RAGE/NF-kB and tight junction proteins are needed to be further investigated.

\section{Conclusion}

In conclusion, AGEs may cause abnormal expressions of tight junction-associated integral membrane proteins (ZO-1 and Occludin) in placental vascular endothelial cells via RAGE/NF-kB signaling pathway, thereby damaging the integrity of endothelial cell monolayers and increasing paracellular permeability. Genes in RAGE/NF-KB signaling pathway may be expected to be regarded as potential therapeutic targets for cell permeability dysfunction. However, the effects of AGEs on other signaling pathways and tight junction-associated proteins remain to be further studied. In addition, the abnormal increase of vascular permeability was always the early event of angiogenesis, and it was worthwhile to further investigate the relationship between AGEs-induced hyper-permeability and barrier dysfunction, and angiogenesis in BeWo cells. The results in our study would help to provide a novel candidate target for treatment of placental barrier dysfunction in gestational diabetes. 


\section{List Of Abbreviations}

AGEs, advanced glycation end products; IEJs, interendothelial junctions; BSA, bovine serum albumin; PBS, phosphate-buffered saline; RAGE, receptor for advanced glycation end products; PDTC, ammonium pyrrolidinedithiocarbamate; RT-qPCR, Real-time quantitative polymerase chain reaction; ZO-1, zonula occluding 1.

\section{Declarations}

\section{Ethical approval and consent to participate}

Not applicable.

\section{Consent for publication}

Not applicable.

\section{Availability of data and materials}

The datasets used and/or analysed during the current study are available from the corresponding author on reasonable request.

\section{Competing interests}

The authors declare that they have no competing interests.

\section{Funding}

This work was financially supported by the Natural Science Foundation of Jiangsu Province (No. BK20151420) and the Natural Science Foundation of China (No.81771628).

\section{Authors' contribution}

YHS and LJ contributed to the study conception and design. Material preparation, data collection and analysis were performed by YHS, JQ and QFZ. The first draft of the manuscript was written by YHS and YH. Manuscript editing was revised by DDS and LJ. All authors read and approved the final manuscript.

\section{Acknowledgements}

Not applicable.

\section{References}

1. Sun YN, Liu YJ, Zhang L, Ye Y, Lin LX, Li YM, et al. Expression of organic anion transporting polypeptide $1 \mathrm{c} 1$ and monocarboxylate transporter 8 in the rat placental barrier and the compensatory 
response to thyroid dysfunction. PloS one. 2014;9(4):e96047. http://doi.org/ 10.1371/journal.pone.0096047

2. Tsatsaris V, Fournier T, Winer N. [Pathophysiology of preeclampsia]. Annales francaises d'anesthesie et de reanimation. 2010;29(3):e13-8. http://doi.org/ 10.1016/j.jgyn.2007.08.003

3. Gortazar L, Flores-Le Roux JA, Benaiges D, Sarsanedas E, Paya A, Mane L, et al. Trends in prevalence of gestational diabetes and perinatal outcomes in Catalonia, Spain, 2006 to 2015: the Diagestcat Study. Diabetes/metabolism research and reviews. 2019;35(5):e3151.

4. Coustan DR, Lowe LP, Metzger BE, Dyer AR. The Hyperglycemia and Adverse Pregnancy Outcome (HAPO) study: paving the way for new diagnostic criteria for gestational diabetes mellitus. American journal of obstetrics and gynecology. 2010;202(6):654 e1-6.

5. Monnier VM, Sun W, Sell DR, Fan X, Nemet I, Genuth S. Glucosepane: a poorly understood advanced glycation end product of growing importance for diabetes and its complications. Clinical chemistry and laboratory medicine. 2014;52(1):21-32. http://doi.org/ 10.1515/cclm-2013-0174

6. Singh VP, Bali A, Singh N, Jaggi AS. Advanced glycation end products and diabetic complications. The Korean journal of physiology \& pharmacology : official journal of the Korean Physiological Society and the Korean Society of Pharmacology. 2014;18(1):1-14. http://doi.org/ 10.4196/kjpp.2014.18.1.1

7. Guo XH, Huang QB, Chen B, Wang SY, Li Q, Zhu YJ, et al. Advanced glycation end products induce actin rearrangement and subsequent hyperpermeability of endothelial cells. APMIS : acta pathologica, microbiologica, et immunologica Scandinavica. 2006;114(12):874-83. http://doi.org/ 10.1111/j.1600-0463.2006.apm_372.x

8. Sheikpranbabu S, Haribalaganesh R, Lee KJ, Gurunathan S. Pigment epithelium-derived factor inhibits advanced glycation end products-induced retinal vascular permeability. Biochimie. 2010;92(8):1040-51. http://doi.org/ 10.1016/j.biochi.2010.05.004

9. Bartakova V, Kollarova R, Kuricova K, Sebekova K, Belobradkova J, Kankova K. Serum carboxymethyl-lysine, a dominant advanced glycation end product, is increased in women with gestational diabetes mellitus. Biomedical papers of the Medical Faculty of the University Palacky, Olomouc, Czechoslovakia. 2016;160(1):70-5. http://doi.org/ 10.5507/bp.2015.045

10. Guosheng L, Hongmei S, Chuan N, Haiying L, Xiaopeng Z, Xianqiong L. The relationship of serum AGE levels in diabetic mothers with adverse fetal outcome. Journal of perinatology : official journal of the California Perinatal Association. 2009;29(7):483-8. http://doi.org/ 10.1038/jp.2009.12

11. Harsem NK, Braekke K, Torjussen T, Hanssen K, Staff AC. Advanced glycation end products in pregnancies complicated with diabetes mellitus or preeclampsia. Hypertension in pregnancy. 2008;27(4):374-86. http://doi.org/ 10.1080/10641950802000968

12. Semba RD, Nicklett EJ, Ferrucci L. Does accumulation of advanced glycation end products contribute to the aging phenotype? The journals of gerontology Series A, Biological sciences and medical sciences. 2010;65(9):963-75. http://doi.org/ 10.1093/gerona/glq074 
13. Shapiro BP, Owan TE, Mohammed SF, Meyer DM, Mills LD, Schalkwijk CG, et al. Advanced glycation end products accumulate in vascular smooth muscle and modify vascular but not ventricular properties in elderly hypertensive canines. Circulation. 2008;118(10):1002-10. http://doi.org/ 10.1161/CIRCULATIONAHA.108.777326

14. Araujo JR, Pereira AC, Correia-Branco A, Keating E, Martel F. Oxidative stress induced by tertbutylhydroperoxide interferes with the placental transport of glucose: in vitro studies with BeWo cells. European journal of pharmacology. 2013;720(1-3):218-26. http://doi.org/ 10.1016/j.ejphar.2013.10.023

15. Xie J, Mendez JD, Mendez-Valenzuela V, Aguilar-Hernandez MM. Cellular signalling of the receptor for advanced glycation end products (RAGE). Cellular signalling. 2013;25(11):2185-97. http://doi.org/ 10.1016/j.cellsig.2013.06.013

16. Tang X, Qin Q, Xie X, He P. Protective effect of sRAGE on fetal development in pregnant rats with gestational diabetes mellitus. Cell biochemistry and biophysics. 2015;71(2):549-56. http://doi.org/ 10.1007/s12013-014-0233-9

17. Xu G, Ao R, Zhi Z, Jia J, Yu B. miR-21 and miR-19b delivered by hMSC-derived EVs regulate the apoptosis and differentiation of neurons in patients with spinal cord injury. Journal of cellular physiology. 2019;234(7):10205-17. http://doi.org/ 10.1002/jcp.27690

18. Li P, Chen D, Cui Y, Zhang W, Weng J, Yu L, et al. Src Plays an Important Role in AGE-Induced Endothelial Cell Proliferation, Migration, and Tubulogenesis. Frontiers in physiology. 2018;9:765. http://doi.org/ 10.3389/fphys.2018.00765

19. Wang Q, Fan A, Yuan Y, Chen L, Guo X, Huang X, et al. Role of Moesin in Advanced Glycation End Products-Induced Angiogenesis of Human Umbilical Vein Endothelial Cells. Scientific reports. 2016;6:22749. http://doi.org/ 10.1038/srep22749

20. de Ranitz-Greven WL, Kaasenbrood L, Poucki WK, Hamerling J, Bos DC, Visser GH, et al. Advanced glycation end products, measured as skin autofluorescence, during normal pregnancy and pregnancy complicated by diabetes mellitus. Diabetes technology \& therapeutics. 2012;14(12):1134-9. http://doi.org/ 10.1089/dia.2012.0120

21. Cerofolini L, Giuntini S, Barbieri L, Pennestri M, Codina A, Fragai $M$, et al. Real-Time Insights into Biological Events: In-Cell Processes and Protein-Ligand Interactions. Biophysical journal. 2019;116(2):239-47. http://doi.org/ 10.1016/j.bpj.2018.11.3132

22. Baluk P, Fuxe J, Hashizume H, Romano T, Lashnits E, Butz $S$, et al. Functionally specialized junctions between endothelial cells of lymphatic vessels. Journal of Experimental Medicine, 2007; 204(10):2349-62. http://doi.org/ 10.1084/jem.20062596

23. Komarova YA, Kruse K, Mehta D, Malik AB. Protein Interactions at Endothelial Junctions and Signaling Mechanisms Regulating Endothelial Permeability. Circulation Research. 2017; 120(1), 179206. http://doi.org/ 10.1161/CIRCRESAHA.116.306534

24. Leach L, Lammiman MJ, Babawale MO, Hobson SA, Bromilou B, Lovat S, et al. Molecular organization of tight and adherens junctions in the human placental vascular tree. Placenta. 
2000;21(5-6):547-57. http://doi.org/ 10.1053/plac.2000.0541

25. Itoh M, Nakadate K, Matsusaka T, Hunziker W, Sugimoto H. Effects of the differential expression of ZO-1 and ZO-2 on podocyte structure and function. Genes to cells : devoted to molecular \& cellular mechanisms. 2018;23(7):546-556. http://doi.org/ 10.1111/gtc.12598

26. Forster $\mathrm{C}$. Tight junctions and the modulation of barrier function in disease. Histochemistry and cell biology. 2008;130(1):55-70. http://doi.org/ 10.1007/s00418-008-0424-9

27. Sun YN, Liu LB, Xue YX, Wang P. Effects of insulin combined with idebenone on blood-brain barrier permeability in diabetic rats. Journal of neuroscience research. 2015;93(4):666-677. http://doi.org/ 10.1002/jnr.23511

28. Al-Sadi R, Guo S, Ye D, Rawat M, Ma TY. TNF-alpha Modulation of Intestinal Tight Junction Permeability Is Mediated by NIK/IKK-alpha Axis Activation of the Canonical NF-kappaB Pathway. The American journal of pathology. 2016;186(5):1151-65. http://doi.org/ 10.1016/j.ajpath.2015.12.016

29. Hudson BI, Moon YP, Kalea AZ, Khatri M, Marquez C, Schmidt AM, et al. Association of serum soluble receptor for advanced glycation end-products with subclinical cerebrovascular disease: the Northern Manhattan Study (NOMAS). Atherosclerosis. 2011;216(1):192-8. http://doi.org/ 10.1016/j.atherosclerosis.2011.01.024

30. Thomas MC, Soderlund J, Lehto M, Makinen VP, Moran JL, Cooper ME, et al. Soluble receptor for AGE (RAGE) is a novel independent predictor of all-cause and cardiovascular mortality in type 1 diabetes. Diabetologia. 2011;54(10):2669-77. http://doi.org/ 10.1007/s00125-011-2186-5

31. Anisuzzaman, Hatta T, Miyoshi T, Matsubayashi M, Islam MK, Alim MA, et al. Longistatin in tick saliva blocks advanced glycation end-product receptor activation. The Journal of clinical investigation. 2014;124(10):4429-44. http://doi.org/ 10.1172/JCI74917

32. Sessa L, Gatti E, Zeni F, Antonelli A, Catucci A, Koch M, et al. The receptor for advanced glycation endproducts (RAGE) is only present in mammals, and belongs to a family of cell adhesion molecules (CAMs). PloS one. 2014;9(1):e86903. http://doi.org/ 10.1371/journal.pone.0086903

33. Carrozza C, Lapolla R, Gervasoni J, Rota CA, Locantore P, Pontecorvi A, et al. Assessment of salivary free cortisol levels by liquid chromatography with tandem mass spectrometry (LC-MS/MS) in patients treated with mitotane. Hormones (Athens). 2012;11(3):344-9. http://doi.org/ 10.14310/horm.2002.1363

34. Raj V, Ojha S, Howarth FC, Belur PD, Subramanya SB. Therapeutic potential of benfotiamine and its molecular targets. European review for medical and pharmacological sciences. 2018;22(10):3261-73. http://doi.org/ 10.26355/eurrev_201805_15089

35. Goldin A, Beckman JA, Schmidt AM, Creager MA. Advanced glycation end products: sparking the development of diabetic vascular injury. Circulation. 2006;114(6):597-605. http://doi.org/ 10.1161/circulationaha.106.621854

36. Sick E, Brehin S, Andre P, Coupin G, Landry Y, Takeda K, et al. Advanced glycation end products (AGEs) activate mast cells. British journal of pharmacology. 2010;161(2):442-55. http://doi.org/ 10.1111/j.1476-5381.2010.00905.x 
37. Hirose A, Tanikawa T, Mori H, Okada Y, Tanaka Y. Advanced glycation end products increase endothelial permeability through the RAGE/Rho signaling pathway. FEBS letters. 2010;584(1):61-6. http://doi.org/ 10.1016/j.febslet.2009.11.082

38. Feng L, Zhu MM, Zhang MH, Wang RS, Tan XB, Song J, et al. Protection of glycyrrhizic acid against AGEs-induced endothelial dysfunction through inhibiting RAGE/NF-kappaB pathway activation in human umbilical vein endothelial cells. Journal of ethnopharmacology. 2013;148(1):27-36. http://doi.org/ 10.1016/j.jep.2013.03.035

\section{Table}

Table 1 The effects of fecal microbiota transplantation on serum IL-10, IL-17, TNF- $\alpha$, and TGF- $\beta$ levels in mice

\begin{tabular}{ccccc}
\hline Types & IL-10 (pg/ml) & IL-17 (pg/ml) & TNF- $₫ \llbracket \mathrm{ng} / \mathrm{ml}$ & TGF- $\beta(\mathrm{ng} / \mathrm{ml})$ \\
\hline CTRL & $25.34 \pm 4.48$ & $11.98 \pm 2.92$ & $395.39 \pm 26.57$ & $26.23 \pm 6.51$ \\
D-GalN & $9.59 \pm 3.15^{*}$ & $30.58 \pm 6.09^{*}$ & $770.26 \pm 98.67 *$ & $229.79 \pm 45.03^{*}$ \\
D-GalN+SS & $14.10 \pm 2.68^{*} \#$ & $19.73 \pm 3.04^{*} \#$ & $513.26 \pm 31.31^{*} \#$ & $155.34 \pm 29.62^{* \#}$ \\
D-GalN+BB & $15.95 \pm 2.07^{*} \#$ & $15.13 \pm 2.75^{*} \#$ & $495.92 \pm 40.71^{*} \#$ & $108.12 \pm 7.87^{*} \#$ \\
\hline
\end{tabular}

* $P \square 0.05$ compared with control group; ${ }^{\#} P \square 0.05$ compared with D-GalN group; $\triangle P \square 0.05$ compared with D-GalN + SS group.

\section{Figures}



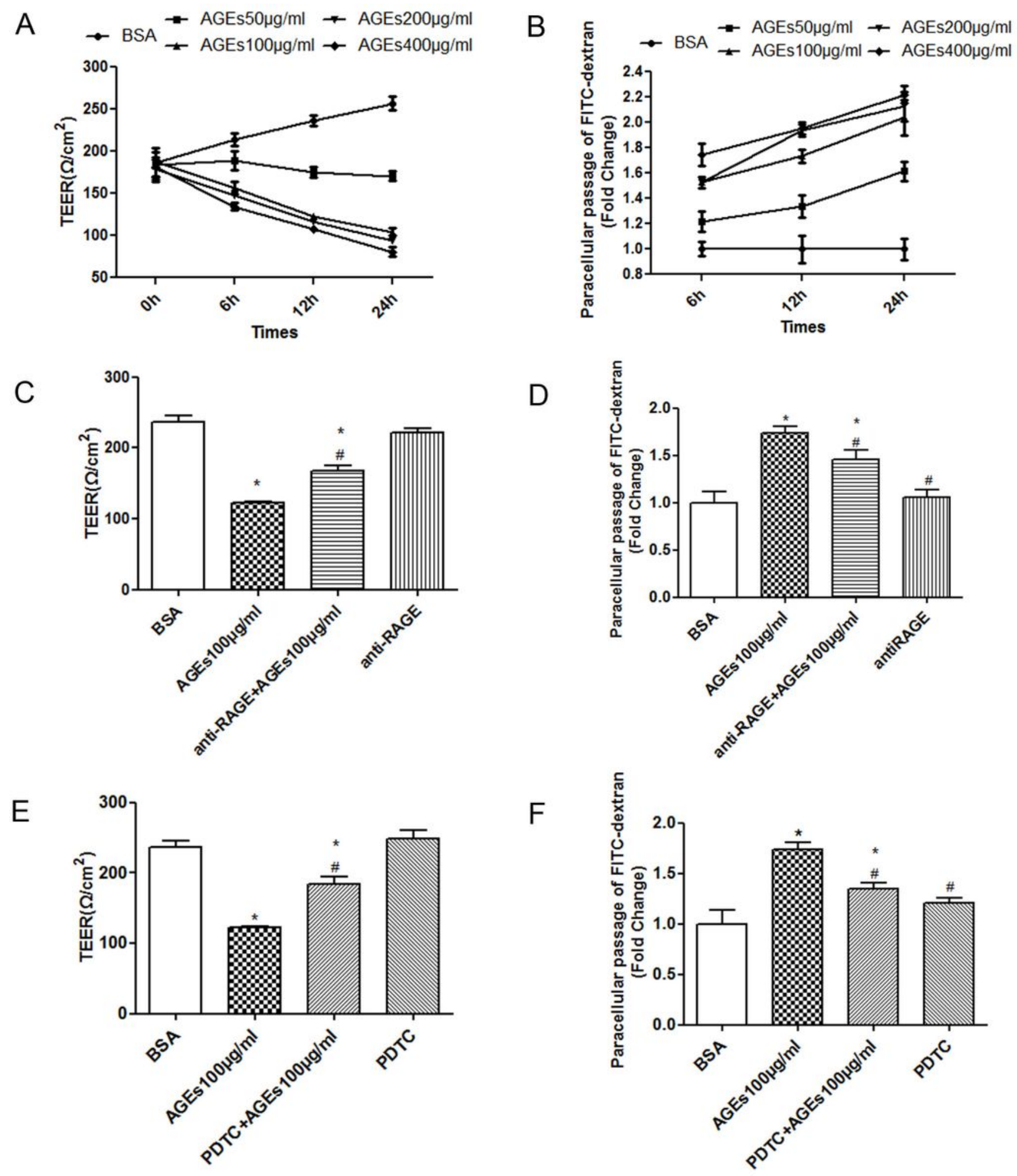

Figure 2

Advanced glycation end products (AGEs) increased cell permeability of BeWo cells. (A) Effects of different concentrations of AGEs on TEER in BeWo cell monolayer at different time. (B) Effects of different concentrations of AGEs on paracellular permeability in BeWo cell monolayer at different time. (C) Effects of anti-RAGE antibody and PDTC on TEER in BeWo cell monolayer induced by AGEs. (D) Effects of PDTC on paracellular permeability in BeWo cell monolayer induced by AGEs. Results were from 
triplicate experiments, and the mean values were shown. Data were shown as the mean \pm standard deviation (SD). ${ }^{*} P<0.05$, compared with the control group (BSA); $\#<<0.05$, compared with the AGEs group.

BSA

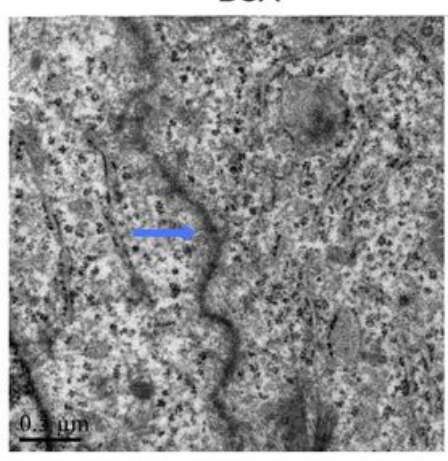

AGES

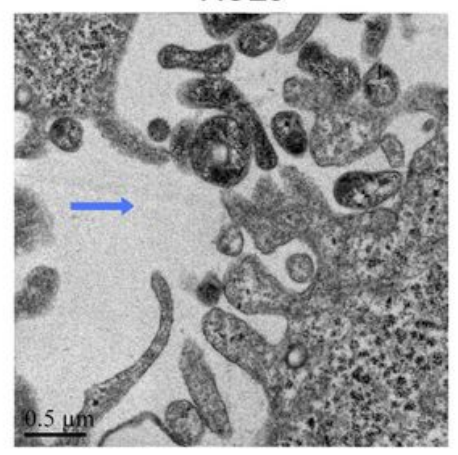

anti-RAGE + AGEs

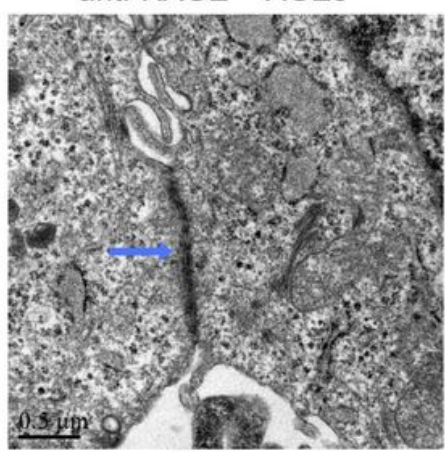

PDTC+AGEs

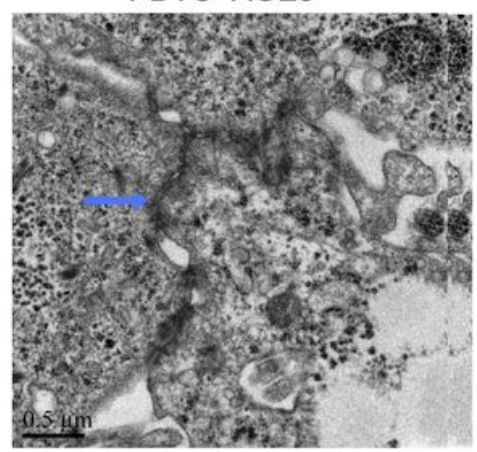

\section{Figure 4}

AGEs disrupted tight junctions of BeWo cells. Transmission electron microscopy was used to observe the tight junction among BeWo cells, and the blue arrows indicated tight junction structure. Images were randomly collected, and representative images were shown. 


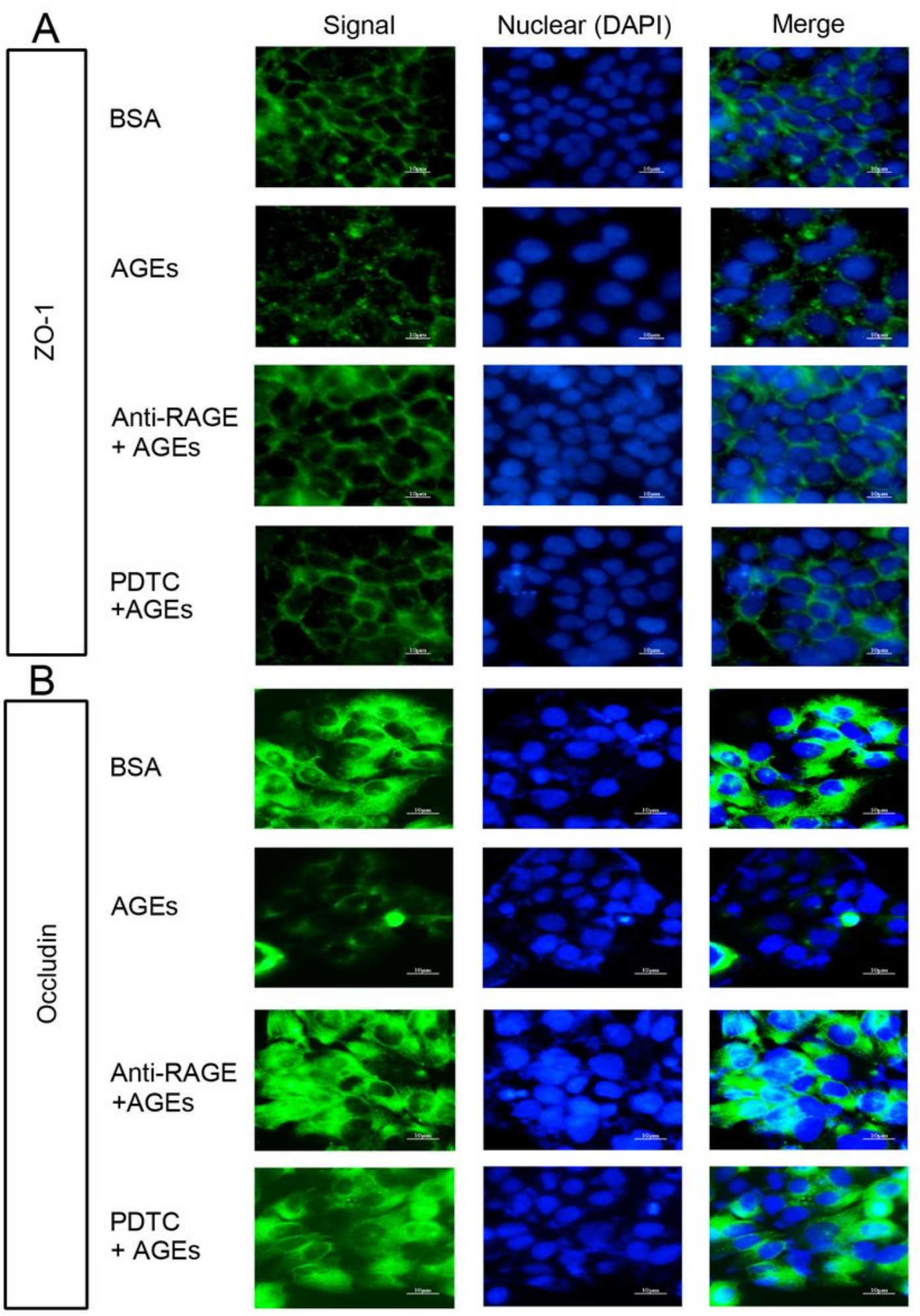

Figure 6

AGEs increased cell permeability by down-regulating the expression of tight junction-asociated proteins in BeWo cells. Immunofluorescence analysis revealed that AGEs greatly decreased relative protein expression levels of ZO-1 (A) and Occludin (B), which could be recovered to normal expression level with co-transfection with anti-RAGE or PDTC. Immunofluorescence Image is randomly collected, and representative images were shown. 
A

\section{ZO-1 \\ Occludin}

RAGE

$N F-K B$

GAPDH

AGEs $100 \mu \mathrm{g} / \mathrm{ml}$

anti-RAGE
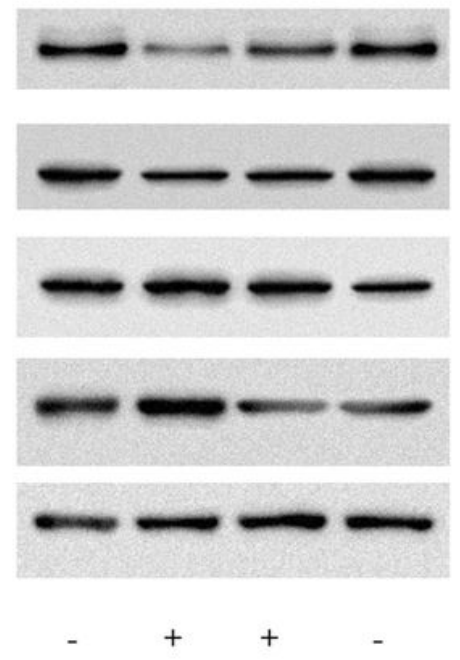

(c)
B

ZO-1

Occludin

RAGE

NF-KB

GAPDH

AGEs $100 \mu \mathrm{g} / \mathrm{ml}$

PDTC
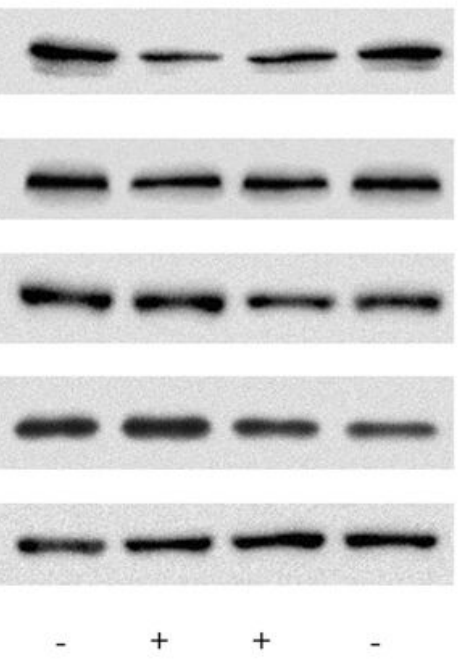

C $\square$ BSA AGEs $\square$ anti-RAGE+AGEs m anti-RAGE

D $\square$ BSA ․ㅡㅁ PDTC+AGEs PDTC
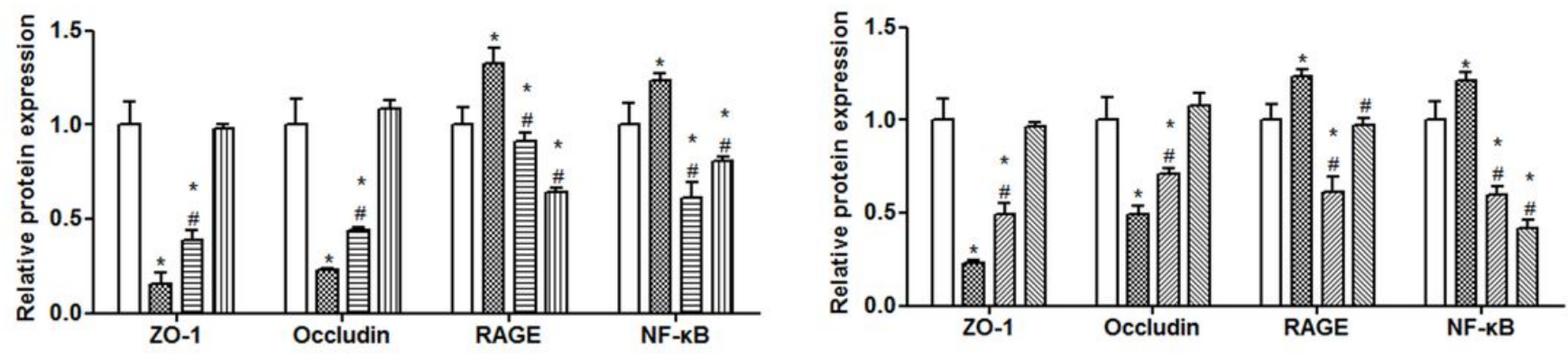

Figure 8

AGEs reduced the relative protein levels of tight junction-associated proteins. (A) Effects of anti-RAGE antibody on protein expression of ZO-1, Occludin, RAGE and NF-kB detected by western blot. (B) Effects of PDTC on protein expression of ZO-1, Occludin, RAGE and NF-kB detected by western blot. (C-D) The levels of ZO-1, Occludin, RAGE and NF-kB by western blot were quantified. Representative blots were from triplicate experiments and data were shown as the mean $\pm S D$. ${ }^{*} P<0.05$, compared with the control group (BSA); \# $\mathrm{P}<0.05$, compared with the AGEs group. 
A
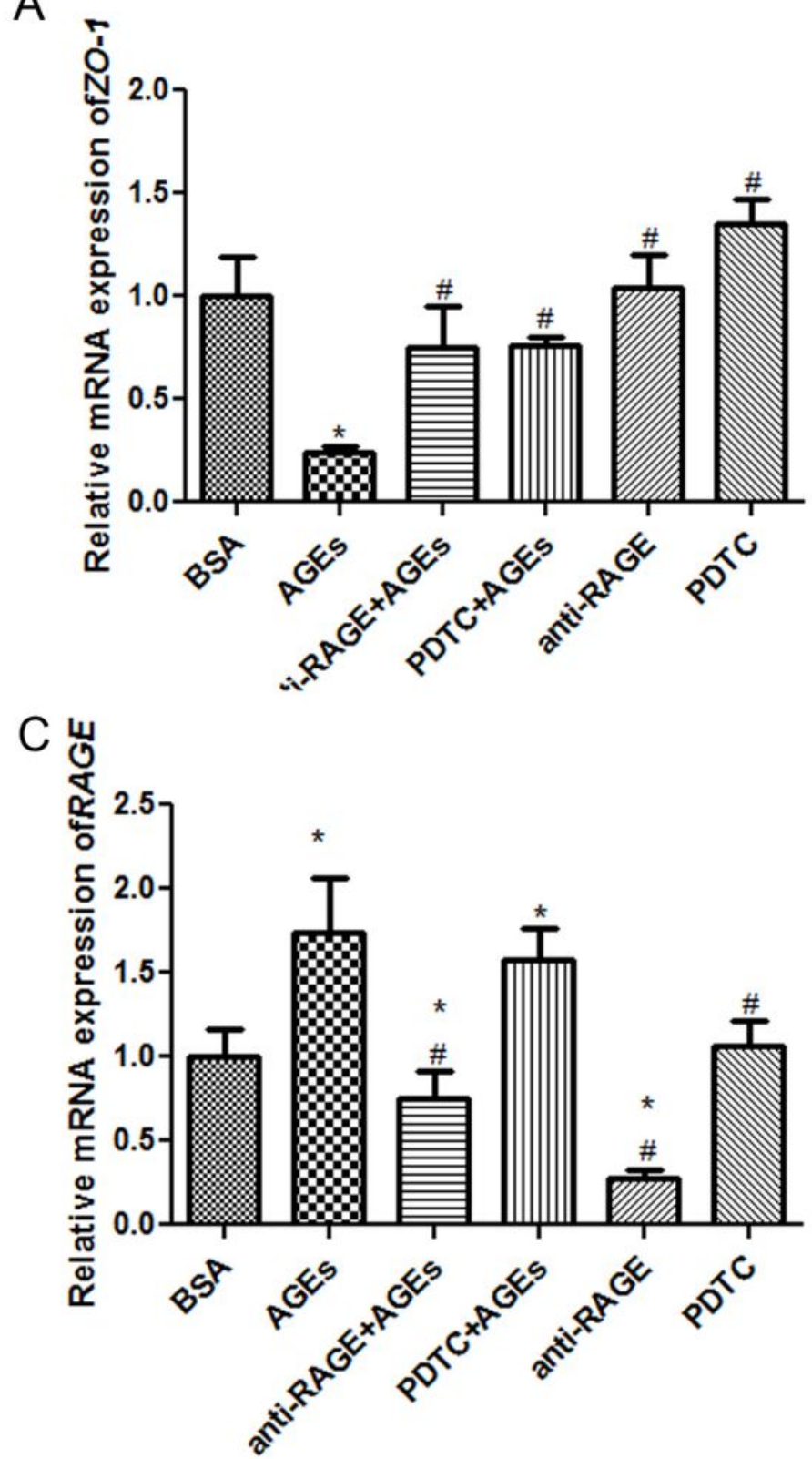

B ํㅗํ

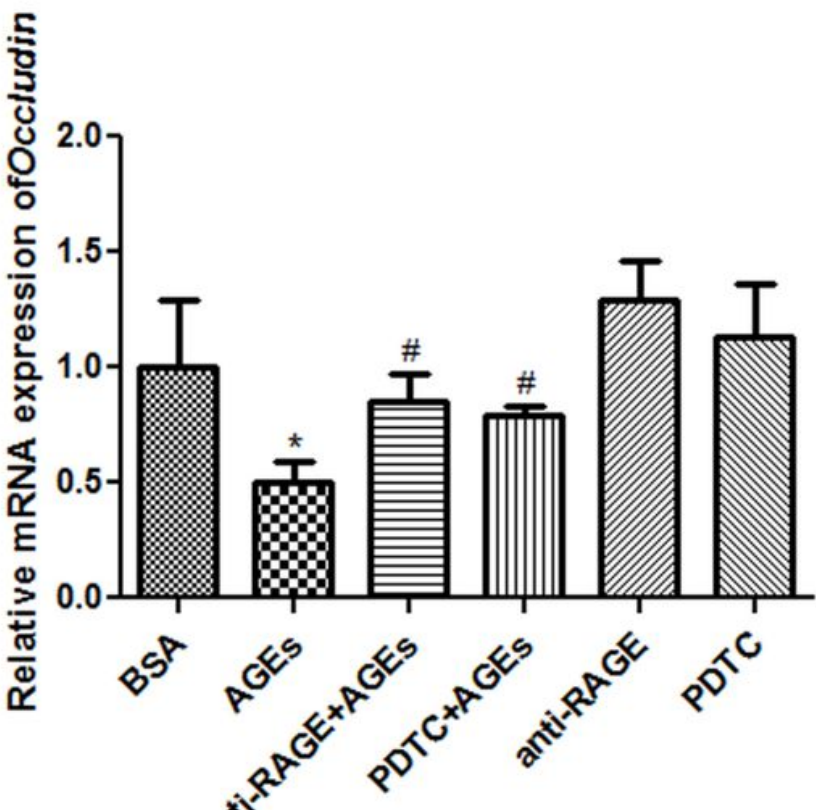

D

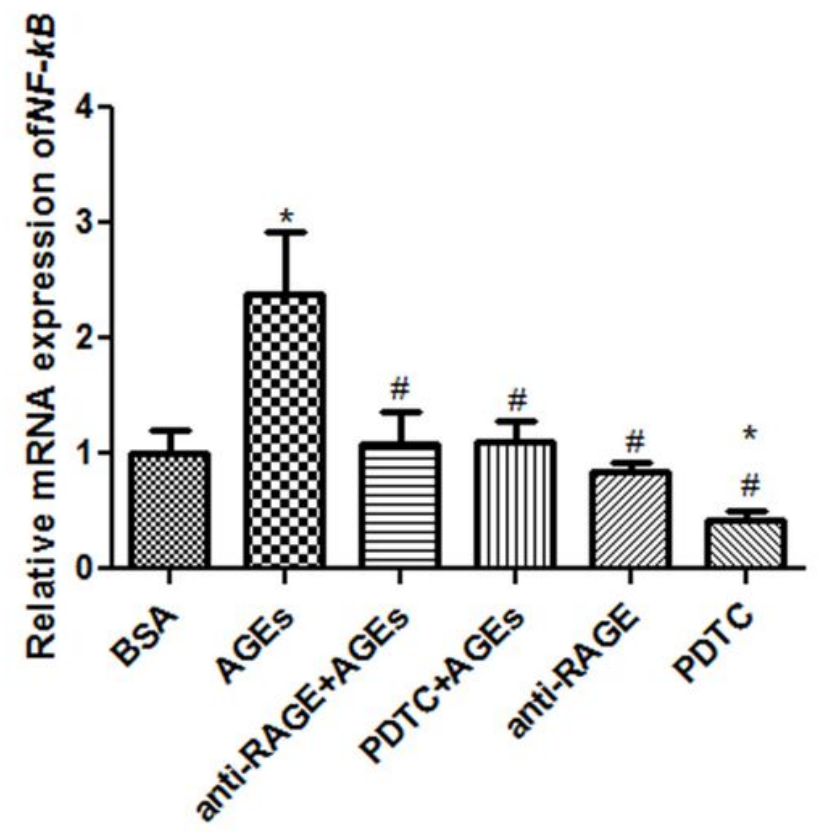

Figure 10

AGEs inhibited the expressions of ZO-1 and Occludin by activating RAGE/NF-kB signaling pathway. (A) The mRNA expression of ZO-1 detected by RT-qPCR. (B) The mRNA expression of Occludin detected by RT-qPCR. (C) The mRNA expression of RAGE detected by RT-qPCR. (D) The mRNA expression of NF-kB detected by RT-Qpcr. Results were from triplicate experiments. Data were shown as the mean $\pm \mathrm{SD}$. *P< 0.05 , compared with the control group (BSA); \# P $<0.05$, compared with the AGEs group.

\section{Supplementary Files}

This is a list of supplementary files associated with this preprint. Click to download. 
- Tables.docx

- Tables.docx

Page 19/19 